\title{
Naturaleza jurídica de los contratos en las empresas sociales del Estado*
}

\author{
Nature of the contracts in \\ social State companies
}

\author{
YOLANDA WONG BALDIRIS
}

\section{Resumen}

La salud es bien superior del hombre y misión esencial de los Estados sociales de derecho como el nuestro, y así lo reconoce nuestra Carta Magna en sus artículos $2^{\circ}$ y 49.

El Estado descentralizó y masificó ese cometido esencial a través de sus empresas sociales, brindándoles herramientas administrativas, patrimoniales y jurídicas propias y especiales.

Las empresas sociales del Estado acuden, para su misión, a la contratación de servicios y bienes, relaciones jurídicas de interés esencialmente público, pero que el Legislador sometió en la Ley 100 de 1993 al derecho privado, con posibilidad de incluir cláusulas exorbitantes públicas que no comulgan con la autonomía de la voluntad de los contratos de derecho privado.

Palabras clave: Empresas sociales del Estado, prestación de servicios de salud, contratación de la salud, ESE, contratación de las ESE, régimen de las ESE, salud

\begin{abstract}
Health is the greatest good of mankind and essential mission of Social States of Law as our own; it is so recognized in our Constitution in Articles 2 and 49.

To this essential role, the State decentralized and massified this good through the State Social companies, thus providing administrative tools, economic and own legal special ones.

State Social Enterprises must to accomplish their mission, procure goods and services, relationships which are essentially of public interest law, but which the legislature submitted with the law 100 of 1993 to private law, with the possibility to include exorbitant clauses that do meet the will autonomy of private law contracts.

Keywords: State social companies, health services, contracting of health, ESE, hiring ESE, ESE regime, health.

* Artículo de reflexión.

** Estudiante de la Maestría de Derecho Contractual Público y Privado, con tutoría de Corina Duque Ayala, docente de la Universidad Santo Tomás.
\end{abstract}




\section{INTRODUCCIÓN}

La salud es un derecho intrínseco al ser humano, que por su naturaleza es misión esencial de los Estados modernos; de allí que en el nuestro se hubiere elevado a una doble categoría constitucional (art. 49): a derecho fundamental y a servicio público. Esta última implica un carácter asistencial que exige para su efectividad normas presupuestales, organizativas y procedimentales a cargo del Estado. En ese sentido, en Sentencia T-636 (agosto 15 de 2007) con ponencia del magistrado Humberto Sierra Porto, se pronunció la Corte Constitucional:

Según el artículo 49 de la Constitución Nacional, la salud tiene una doble connotación -derecho constitucional fundamental y servicio público-. En tal sentido, todas las personas deben poder acceder al servicio de salud y al Estado le corresponde organizar, dirigir, reglamentar y garantizar su prestación de conformidad con los principios de eficiencia, universalidad y solidaridad.

En este orden de ideas, el artículo 49 de la Constitución Nacional dispone que le "[c]orresponde al Estado organizar, dirigir y reglamentar la prestación del servicio de salud a los habitantes [y] (...) establecer las políticas de prestación de servicio de salud por entidades privadas y ejercer su vigilancia y control". Esta facultad que la Constitución le otorga de manera amplia a las instituciones estatales y a los particulares comprometidos con la garantía de prestación del servicio de salud, está conectada con la realización misma del Estado social de derecho y con los propósitos derivados del artículo $2^{\circ}$ de la Constitución.

En esa tónica, el Estado colombiano, por intermedio de su Legislador, desarrolló esa preceptiva constitucional y fue así como expidió la Ley 100 de 1993 por medio de la cual se creó el sistema de seguridad social integral, encomendando la prestación del servicio público asistencial de salud a la nación directamente, y a las entidades territoriales por medio de personas jurídicas de régimen jurídico especial y autónomas administrativa y pre- supuestalmente, denominadas en forma genérica empresas sociales del Estado, cuyo objeto social se definió de forma precisa como “... la prestación de los servicios de salud, como servicio público a cargo del Estado o como parte del servicio público de seguridad social" ${ }^{\prime \prime}$.

Dada la complejidad que implica la prestación de servicios de salud, las entidades prestadoras requieren para su ejercicio y cometido social la celebración de actos jurídicos vinculantes, por lo que el mismo estatuto que las erigió como misioneras de la prestación del servicio de salud las autorizó para contratar. Así, tenemos que el numeral $6^{\circ} \mathrm{de}$ la norma ibídem dispone: "En materia contractual se regirá por el derecho privado, pero podrá discrecionalmente utilizar las cláusulas exorbitantes previstas en el estatuto general de contratación de la administración pública", de donde se evidencia que muy a pesar de responder dicho servicio a intereses generales y públicos, la actividad contractual que celebra para la observancia de su objeto social se somete al régimen privado de contratación, esto es, a la normatividad civil y/o comercial, mas no al Estatuto General de la Contratación, y en ese sentido lo consideran autores como Dávila Vinueza (2003) al decir:

\section{En consecuencia, la actividad contractual de las empresas sociales del Estado a las que aluden las citadas normas, no está sometida en todo a la Ley 80 de 1993, pese a su evidente naturaleza de enti- dades públicas, ya que expresamente la ley determinó que esa materia se rige por el derecho privado (pp. 840-841).}

Ahora bien, las empresas sociales del Estado que requieren celebrar contratos para la prestación de los servicios esenciales de salud que se les ha encomendado deben someterse al derecho privado, no obstante el carácter público -finalísticamente hablando- de esas contrataciones y de que la Ley 1150 de 2007, en el ordinal $C$ del numeral $2^{\circ}$ del ar-

1 Artículo 195, numeral 2º, de la Ley 100 de 1993. 
tículo $2^{\circ}$, determina que es el proceso de selección abreviada del contratista la modalidad de selección para la escogencia del mismo en los contratos de prestación de salud, pero "Sin perjuicio de lo dispuesto en la Ley 100 de 1993", normatividad esta que otorga la facultad discrecional de hacer uso de las denominadas cláusulas exorbitantes de naturaleza totalmente pública, y que a prima facie trastocan principios fundamentales del derecho privado, como la autonomía de la voluntad, que podrían convertir en un híbrido la naturaleza jurídica de ese tipo de contratación de las empresas sociales del Estado.

En atención a ello, en este informe auscultaremos en un primer momento la historia del derecho a la salud como servicio público, a fin de conocer pormenorizadamente cómo este derecho fundamental fue elevado a la categoría de un servicio como mecanismo para hacer eficaz y eficiente su prestación generalizada, y de tal manera dar cumplimiento a ese fin esencial del Estado.

Ahora bien, es en ese proceso evolutivo histórico donde podremos analizar y estudiar los avances que ha habido en Colombia respecto de ese servicio asistencial fundamental como lo es la salud, desde las dos facetas prestacionales que se dan en nuestro país, ya como medio de colaboración con los fines de Estado (ámbito privado), o como cometido estatal (ámbito público), para poder conocer los avances histórico-jurídicos que fueron dando forma y elevando a una dimensión mucho más amplia de lo que es la salud como servicio y que hoy día lo erigen como cometido estatal esencial, pero que el Estado puede controladamente permitir en los particulares como actividad de mercado.

Sin lugar a dudas, nuestra Carta Magna de 1991 trajo consigo un nuevo modelo de Estado donde el núcleo social es su cometido principal, y en ese sentido categorizó al derecho de la salud como fundamental, brindando no solo mayores y mejores coberturas de protección a todos sus ciudadanos, sino herramientas eficaces para su solvencia real, de allí que sea menester adentrarse en el proceso evolutivo que ha tenido en Colombia el derecho a la salud como instituto fundamental que el Estado garantiza en su prestación.

Por último, ahondaremos en este informe en el proceso histórico-evolutivo antes y durante el sistema constitucional vigente que tiene el sistema general de seguridad social en salud, habida cuenta que es de rango constitucional actual que la seguridad social comprende una gama amplia de servicios prestacionales que buscan una cobertura integral del conglomerado social, desempeñando un papel relevante la salud. Este derecho presenta múltiples dimensiones que lo irrogan de contenido y de ámbito de protección estatal, ya en el plano individual de sus asociados como usuarios del sistema o como conglomerado al que se debe proyectar y servir.

Este recorrido histórico evolutivo de la salud como derecho y como ámbito de la seguridad social en escenarios bibliográficos de doctrinantes e investigadores autorizados y jurisprudencia temática, nos permite la realización del informe y concluir la conveniencia jurídica de que el Estado regule con normas de derecho privado la actividad contractual de sus empresas sociales al prestar servicios de salud, como forma de dinamismo de esta actividad. Pero, también, que al mismo tiempo determine su proceso selectivo según normas jurídicas públicas y que posibilite cláusulas netamente públicas, como son las exorbitantes que en sentir de Dromi, R. (1995):

[...] son cláusulas inusuales en el derecho privado, o que incluidas en un contrato de derecho común resultarían ilícitas, por exceder el ámbito de la libertad contractual y contrariar el orden público. Estas estipulaciones tienen por objeto crear en las partes derechos y obligaciones extraños, por su naturaleza, a los cuadros de las leyes civiles o comerciales (p. 315). 
Estas excluyen el principio rector de la contratación privada, como lo es la autonomía de la voluntad.

\section{HISTORIA DEL DERECHO A LA SALUD COMO SERVICIO PÚBLICO}

\section{Evolución de la noción de servicio público en salud}

Antes de ahondar en precisiones respecto del servicio público en salud, se hace necesario tener puntual qué se considera como "servicio público" y qué se ha conceptualizado como "salud" dentro del proceso evolutivo de los derechos del hombre. En esa tónica, tenemos que la Organización Mundial de la Salud (OMS), en el preámbulo de su Constitución', la definió así: "La salud es un estado de completo bienestar físico, mental y social, y no solamente la ausencia de afecciones o enfermedades"; en consideración a ello, autores como C. A. Olano y H.A. Olano (2000) manifiestan respecto del concepto de salud universalmente considerado que:

Todos cuantos se interesan por este tema que ocupa tan elevada jerarquía en la escala de los derechos humanos, no pueden prescindir de preguntarse cuál es el concepto más actualizado y difundido de salud.

Si en lenguaje común los términos salud y enfermedad se consideran compuestos, (salud, ausencia de enfermedad; enfermedad, privación de la salud), expertos de la Organización Mundial de la Salud, OMS, han conceptuado en diversos estudios y documentos que la salud no consiste únicamente en ausencia de enfermedad o dolencia de cualquier naturaleza, sino que "es un estado de completo bienestar físico, mental y social". Ante la dificultad de establecer el conjunto de valores indispensables para definir en qué consiste el bienestar

2 Celebrada en Nueva York del 19 de junio al 22 de julio de 1946, firmada el 22 de julio de 1946 por los representantes de 61 Estados (Official Records of the World Health Organization, № 2, p. 100) y entró en vigor el 7 de abril de 1948. La definición no se ha modificado desde 1948 . -como bien superior de la generalidad de las personas-, se ha querido simplificar el problema propugnado por que el derecho a la salud descienda del firmamento de las abstracciones a uno más realista, como sería el deber concertado de individuo, grupos sociales y estadio, en orden a conjurar los diversos factores que se oponen a que el ser humano pueda ejercer ordinariamente todas sus funciones naturales (p. 645).

Lo anterior nos clarifica que la salud es un concepto intrínseco al hombre, pero no en un contexto o plano netamente biológico-individual del ser humano, sino como ser social, esto es, como expresa Contreras Bautista (2007): “En ese sentido hay que tener en cuenta que la salud abarca los servicios personales, los servicios de salud pública y la relación de la misma con el medio ambiente y el saneamiento básico" (p. 55).

Ahora bien, Contreras Bautista (2009), respecto de la definición del concepto de servicios públicos, dice:

El servicio público se define como toda actividad encaminada a satisfacer necesidades de interés general, bajo los principios de continuidad, adaptación, neutralidad e igualdad. En Colombia, el numeral $3^{\circ}$ del artículo $2^{\circ}$ de la Ley 80 de 1993 se guía por ese parámetro al indicar que se denominan servicios públicos "(I)os que están destinados a satisfacer necesidades colectivas en forma general, permanente y continua, bajo la dirección, regulación y control del Estado, así como aquellos mediante los cuales el Estado busca preservar el orden y asegurar el cumplimiento de sus fines" (p. 40).

Como se observa, los servicios públicos son aquellas necesidades esenciales generales que hacen que el colectivo social de un Estado goce de elementos mínimos de supervivencia. Como tal se erigen en fines del Estado, ya por prestación directa de este o por medio de particulares vigilados por el mismo; en ese sentido los definen autores 
de las teorías modernas, entre ellos el profesor Esguerra Portocarrero (1972). Veamos:

El conjunto de actividades creadas y reguladas por el Estado, cuyo fin se endereza a la realización del bien común, organizadas, desarrolladas y prestadas en forma continua, regular, igual, general y obligatoria, ya sea directamente por el mismo, a través de concesionarios o por simples particulares, mediante procedimientos de derecho público para la satisfacción de las necesidades individuales y colectivas de la sociedad, teniendo como meta un interés general directo o indirecto.

Ahora bien, tenemos que la característica primordial que ha erigido evolutivamente a un servicio a la esfera de público es su esencialidad para con la sociedad, y habida cuenta las esferas amplias que irrogan al derecho a la salud le han brindado tal carácter; por ello hace parte del proceso evolutivo - histórico internacional de lo que es "servicios públicos" que, como enseña Contreras Bautista (2009), tiene cinco fases; a saber:

La evolución histórica del servicio público presenta cinco fases: la policiva, su prestación mediante concesión, prestación directa por el Estado, el Estado empresario y el Estado planificador.

El Estado gendarme, expresión inicial de las ideas liberales, tuvo como papel primordial y limitado la defensa de las libertades individuales mediante la preservación del orden público (policía, ejército y justicia)...

La prestación directa de los servicios por parte del Estado se da a partir del final de la primera guerra mundial, como consecuencia de las carencias económicas y sociales dejadas por la misma y el nacimiento de la URSS como propuesta política. A partir de la segunda posguerra el Estado se vuelve productor de bienes de la economía, como un agente más del mercado. [...] La presente etapa se expresa mediante el papel del Estado planeador de la economía pública y garantizadora de la prestación de los servicios públicos bajo condiciones de mercado (p. 41).
Ahora bien, la evolución de la prestación de los servicios públicos en nuestra historia se dio en cuatro etapas, a saber: la primera, desde finales del siglo XIX hasta inicios del XX, caracterizada por servicios provistos por particulares y en ámbitos territoriales específicos. Una segunda etapa surgida a mediados del siglo pasado, motivada por la insuficiencia en las satisfacciones del creciente volumen de necesidades y que, por lo mismo, se destacó por el fomento del Estado y la regionalización de la prestación de los servicios. Una tercera etapa surgida de la deficiencia de los municipios para satisfacer los servicios, y cuya nota predominante fue su estatalización, pero con concepción comercial y asistencialista que no logró fortalecerse por las falencias administrativas y la conmocionada situación social e institucional de finales de los años noventa. Y una cuarta etapa novedosa y actual, surgida de las entrañas del Estado moderno que se erigió la Carta Magna de 1991, y la nueva estructura de Estado social de derecho que plasmó, categorizó el interés general y elevó a fundamentales derechos que lo exigían por su naturaleza esencial para el hombre, en especial la salud, a la que no le bastó tal condición, sino también la de fuente primordial de la seguridad social. Ello no fue gratuito; obedece al tratamiento de derecho humano que históricamente ha recibido y que trasciende la concepción biológica del hombre, para convertirse en factor económico, social y cultural esencial del Estado, y como tal de su interés y cometido. Por este motivo el Constituyente de la nueva Carta Magna lo elevó no solo a la categoría de derecho humano fundamental, sino también a la de servicio público esencial y parte integral de la seguridad social. Estos rangos son el fruto de consensos internacionales que fueron instrumentalizando (Declaración Universal de los Derechos Humanos de 1948, arts. 22 y 25; Pacto Internacional de Derechos Económicos, Sociales y Culturales, arts. 9 y 12; Declaración Americana de Derechos y Deberes del Hombre) la protección de la salud a nivel internacional, pero con pro- 
yecciones e institucionalizaciones nacionales; he allí del fundamento de ser derecho fundamental integrado al sistema general de seguridad social y servicio público, que, en sentir del profesor Contreras Bautista, le imprime características propias habida cuenta el sometimiento a tres principios; veamos:

La salud como servicio público es de carácter obligatorio y se presta bajo la dirección, coordinación y control del Estado, con base en los principios de eficiencia, universalidad y solidaridad. La eficiencia del sistema es la mejor obtención y utilización de los recursos para alcanzar la universalidad, tanto desde el punto de vista de la cobertura, como de la calidad en el servicio por suministrar, máxime cuando esto último es lo esencial para preservar los derechos fundamentales a la vida, a la integridad personal y a la dignidad humana (p. 120).

\section{Evolución del servicio prestacional de la salud desde el sector público y privado}

Ha sido el proceso evolutivo del concepto de salud el que hace que el margen de su cubrimiento encuentre diferentes formas a lo largo de la historia no solo universal, sino también colombiana; en esa tónica tenemos que la salud, en criterio de la Organización Mundial de la Salud, es “Un estado de completo bienestar físico, mental y social, y no solamente la ausencia de molestias y enfermedades". En ese sentido internacional e histórico abarca al ser humano individualmente considerado, a la salud pública y su relación con el ambiente y el saneamiento básico; es por ello que doctrinalmente se considera la estructuración de tres modelos mediante los cuales se pretendió solventar las exigencias de la prestación del servicio de salud como obligación estatal, esto es, las formas de institucionalizar ese servicio, ya fuere porque el Estado asuma el compromiso solo o compartido con el sector privado, para atender las necesidades sociales en materia de salud, en cuyo evento la presenta como un sistema económico y para su sostenibilidad se vale del sector privado.
En ese sentido se ha expresado Contreras Bautista:

Según el tipo y nivel de cobertura, la forma de financiación, modalidad de provisión de los servicios, orientación del sistema y organización estructural y funcional del mismo, en los Estados occidentales existen tres modelos: liberal, de seguridad social y de servicio nacional de salud.

El modelo liberal o de seguros privados se caracteriza por la no intervención del Estado para asistir en salud a la población (excepto en los casos de las personas indigentes), donde el acceso a los servicios están condicionados a su pago directo o a la contratación de una póliza de seguros, individual o empresarial, la cual no es obligatoria y está regida por las leyes del mercado.

[...] El modelo de seguridad social o modelo Bismark se basa en un sistema de seguros obligatorio, regulado y tutelado por el Estado, cuya cobertura y financiación está asociada a la actividad productiva (empresarios, trabajadores y aportes estatales), pero últimamente se viene transformando hacia la cobertura universal mediante decisiones institucionales de los Estados para garantizar la asistencia básica en salud a toda la población, tal y como lo está desarrollando Colombia de acuerdo con lo establecido en la Constitución Política y las leyes 100 de 1993 y 1122 de 2007.

[...] El modelo de servicio nacional de salud o Beveridge es un sistema bajo titularidad estatal y financiación mayoritaria presupuestal pública el cual se rige por los principios de la universalidad (atención a toda la población como derecho), equidad (libre acceso) e integralidad (servicio integrado para la prevención, promoción y recuperación de la salud), con predominio de la atención terciaria (hospitalaria), lo cual demanda mayor cantidad de recurso (p. 96).

Los modelos expuestos no son otra cosa que respuestas institucionales acordes con el carácter dado dentro de cada Estado a la prestación de la salud, pero por sobre todo al contenido de derecho humano que se erige en el contexto internacional 
a través del derecho internacional de esta índole, verbigracia: la Declaración Universal de los Derechos Humanos (art. 25), el Pacto Internacional de Derechos Económicos, Sociales y Culturales (art. 9) y demás protocolos y convenciones de este tipo, mismas que por el fenómeno sano de la globalización de los derechos humanos se han recogido dentro de las cartas constitucionales de los países al adoptar sus modelos de Estado, como el nuestro que se erige como Estado social de derechos, o la de Chile que, según autores como Contreras Bautista, es la referencia constitucional inmediata de la categoría a la que elevamos la salud. Veamos:

La Carta de Chile que parece ser el referente inmediato para Colombia en la materia, consagra el derecho a la protección de la salud a cargo del Estado, quien protege el libre e igualitario acceso a las acciones de promoción, protección y recuperación de la salud, y de rehabilitación del individuo; coordina y controla lo relacionado con la misma, y tiene el deber preferente de garantizar la ejecución de las acciones de salud, cuya prestación puede ser pública o privada bajo el derecho de libre escogencia de afiliación.

También prescribe el derecho a la seguridad social, para el cual la acción del Estado debe dirigirse a garantizar el acceso a todos los habitantes al goce de presentaciones básicas uniformes otorgadas a través de instituciones públicas o privadas, y a supervigilar el adecuado ejercicio de dicho derecho. Para las prestaciones de ambos derechos la ley puede establecer el cobro de cotizaciones obligatorias (Constitución Política de Chile, artículo 19, numerales 9 y 18).

Ahora bien, ya en el plano de Colombia es claro que el escenario de la salud fue uno antes de la Constitución de 1991, en la cual se partió de una precaria conformación del sistema de salud básicamente higienista asumido por la deficiente red pública, con colaboración de beneficencia del sector privado para con los sectores más pobres y régimen de demanda de servicios, y otro el escenario bajo la égida de la Ley 100 de 1993 y la
Carta Magna que nos regenta, en donde la salud adquirió la connotación de derecho fundamental, de servicio público y de seguridad social, en donde la cobertura del sistema obliga al Estado a solventar dicho derecho a toda la colectividad de forma eficiente y eficaz, acudiendo al sector privado para poder ser viable prestacional, asistencial y financieramente el sistema implementado. En ese sentido, dice Contreras Bautista:

Hasta 1994 en Colombia el sector salud se encontraba organizado bajo tres sistemas de financiación y prestación, el privado (régimen de demanda), el público (régimen de oferta) y el de la seguridad social (régimen de oferta), con recursos desiguales, organización diferente, objetivos poblacionales distintos, donde coexistían la falta de cobertura y de calidad, todo lo cual reflejaba y retroalimentaba una seria desigualdad socio-económica.

El sistema privado era el más antiguo y el que tenía mayor cobertura. El sistema público se fundamentó en el concepto asistencialista y estaba dirigido a los más pobres. El cual se institucionaliza en 1946 con la creación del Ministerio de Higiene y se fortalece con el diseño del Plan Hospitalario Nacional de 1968 y con la formulación de un sistema nacional de salud en 1975.

[...] el seguro social se inspiró en los modelos de Bismark y Beveridge y nace con la creación de la Caja Nacional de Previsión para atender servidores públicos (Ley 6 de 1945) y del Instituto de Seguros Sociales para prestar servicios a los trabajadores del sector privado formal de la economía (Ley 90 de 1946), el cual debía financiarse tripartitamente (Estado, patronos, trabajadores) a partir de gravámenes salariales.

Tal organización de la salud era inequitativa en la prestación de los servicios y en la financiación, porque ambas actividades corrían a cargo del sector privado en su mayor parte, frente al seguro social y al sector público.

[...] La Constitución Política de Colombia de 1991 asumió la prestación de la salud 
individual mediante un sistema de asistencia indirecta, adoptando para ello el modelo económico de prestación de la salud de competencia regulada o de separación de funciones propuesto por Enthoven, bajo un aire de economía neoinstitucional, a partir del hecho mismo de elevarlo a norma de rango fundacional que personifica su organización política como Estado social de derecho (p. 103).

Ya en el plano de la Constitución de 1991, la salud es derecho fundamental con medios constitucionales (tutela) y legales de amparo por las demás ramas del poder estatal cuando se niega la prestación o es deficitaria; servicio público como finalidad de Estado y cuya prestación corresponde a este de forma eficaz y eficiente, asumiendo su control y vigilancia, ya con la red pública del sistema, siempre haciendo respetar los principios orientadores del sistema; y actividad económica, que los particulares pueden ejercer como promotores de salud, como IPS, en fin, como agentes del mercado de salud; así lo expresa la Corte Constitucional en Sentencia C-974 de 2002; veamos:

En ese contexto, si bien los particulares pueden concurrir a la prestación del servicio público de salud y el Estado tiene el deber de garantizar que lo hagan en condiciones de libertad económica y libre competencia, no es menos cierto que en ejercicio de las responsabilidades que les corresponde conforme a la Constitución, el Estado puede intervenir en orden a asegurar que el sistema de seguridad social, con sus componentes públicos y privados, responda, en este caso, a las efectivas necesidades de salud de la población y que los recursos de naturaleza pública que lo conforman se utilicen de la manera que mejor respondan a esos objetivos.

\section{Evolución de la prestación del servicio de salud como garantía del Estado}

La evolución de la salud como servicio público a cargo del Estado en Colombia ha sido bastante compleja dada la gran cantidad de causas externas e internas que influyeron en su formación, pero a gran escala puede analizarse en el contexto de nuestro país en tres fases, evidenciables por las normatividades que lo regulaban como garantía, a saber: la primera se circunscribe a un periodo comprendido entre la promulgación de la Constitución de 1886 y mediados del año 1970, fase esta que se caracterizó porque predominó un "modelo higienista", como lo consideran los estudiosos del tema. Habida cuenta, el interés y provisión de la salubridad pública se circunscribía casi que de forma exclusiva a atender políticas netamente sanitarias, dejando de lado la atención preventiva y curativa en salud del conglomerado social, que debían sufragar los propios usuarios que tenían esa posibilidad económica de acceder a esos servicios, o por algunas instituciones religiosas de caridad en tratándose de personas menos favorecidas.

Durante esta etapa, el Estado conformó una Junta Central de Higiene (1888) cuyo fin era el de adecuación de la legislación nacional a las convenciones sanitarias internacionales, para lograr acogida mundial como mercado de inversiones extranjeras. Para este evento se impulsaban medidas sanitarias portuarias que los demás países exigían como requisitos para poder establecer el comercio seguro de productos con el país; en esa meta nacional se acogieron las formulaciones mundiales que imponían organismos internacionales, como el Consejo Interamericano Económico y Social de la Organización de Estados Americanos (OEA), celebrado en 1961 en la ciudad de Punta del Este, Uruguay, que indicó que la salud se debía vincular al desarrollo socioeconómico de los países.

Este lapso fue formativo pero proyectado hacia metas distantes de la salud pública; sin embargo, en el trasegar de las exigencias internacionales se implementaron programas encaminados a ese fin general de la salud como función estatal, aunque fuere en sectores determinados de la población. Destacamos que para el año 1945 se crea la Caja Nacional de Previsión como forma de atender las exigencias de salud de los empleados vinculados 
al sector público. Ya en un paso más importante para lo que viene a ser el sistema de salud colombiano, para el año 1946 (Ley 90) se crea el Instituto Colombiano de Seguros Sociales (ICSS) que posibilitó la extensión del nivel de atención en salud a los empleados del sector privado formal; sin embargo, el seguro social colombiano en ese momento se había inspirado en el modelo alemán bismarckiano, que contemplaba los seguros sociales obligatorios, en donde la salud solo se brindaba como protección a las necesidades sociales de los trabajadores asalariados de menores ingresos, esto es, la implementación del sistema de salud seguía siendo precaria y sectorizada, dejando de lado la extensión de la cobertura poblacionalmente hablando a la que se sometía a la beneficencia. No había la idea constitucional y menos legal de la asistencia médica o de salud como un derecho de todos los ciudadanos, ya que se seguía manejando el concepto de "asistencia pública" incluido en la reforma de 1936, que involucraba la idea de una obligación estatal por los pobres, lo cual quedaba corto si se compara con el amplio grupo poblacional en condiciones de pobreza que no tenían atención pública en salud. Para la época, esa situación ya pugnaba con la concepción internacional de las funciones del Estado en esa materia, mismas que debían ampliarse para tener así una red pública de servicios en donde la salud adquiriera el estatus de derecho.

En esa tónica de afrontar los compromisos internacionales en pro de la salud pública se promulgaron innumerables leyes con miras a la estructuración del sistema de salud como compromiso de Estado; así tenemos que para 1963 se establece el Plan Nacional Hospitalario y luego, en 1967, mediante la Ley 65 , se le dieron facultades extraordinarias al Presidente de la República con ese objetivo, lo cual permitió que mediante Decreto 2470 del 25 de septiembre de 1968 se reorganizara el Ministerio de Salud Pública y el sistema nacional de salud (SNS), con miras a procurar la salud de la comunidad. En el año 1969 se expidió la Ley 39 sobre plan hospitalario nacional, mediante la que se proyectó la puesta en funcionamiento de hospitales, los cuales se consolidaron financieramente con la creación, años después, del Fondo Nacional Hospitalario. Este recogía recursos del Instituto Colombiano de Seguros Sociales y los destinó a la construcción e implementación de hospitales públicos, como forma de ampliar esa cobertura de salud a los sectores no cobijados con el sistema implementado al crear el ICSS.

La segunda fase del servicio de salud como garantía estatal recorre temporalmente el lapso comprendido desde el año 1970 hasta 1989, que se caracterizó principalmente por la creación del sistema nacional de salud en el año 1975. En el sentir del profesor Cañón Ortega, se establecieron "mecanismos de coordinación entre los organismos y entidades que conforman el sistema. Buscando fundamentalmente una racionalización de los escasos recursos disponibles para atender a las grandes necesidades de la población", pero bajo una visión de Estado que procuró que los recursos del nivel central del gobierno colombiano, destinados para el sector salud, se dirigieran de forma precisa a la red de instituciones públicas hospitalarias. En este periodo, el servicio de salud se convierte en parte integral de la planeación socioeconómica del país. También se crea un esquema tripartito (Estado - empleadores - empleados) de financiación para la prestación de los servicios de salud a la población trabajadora formal; no obstante, el sistema de salud continuaba con falencias, ya que no suministraba una atención integral en salud a la población de escasos recursos y se centraba más que todo en la clase trabajadora, formalmente hablando. En el año 1970, por exigencias internacionales, se creó la medicina familiar como una forma de asignar de una mejor manera la cobertura de salud encargada a ICSS; no obstante, solo hasta 1975 se posibilitó esa situación de salud para el núcleo familiar del cotizante, pero ello solo fue en determinadas regiones. Mediante Decreto-Ley 433 de 1971, se reorganizó el Seguro Social y se 
estableció el seguro médico familiar, extendiendo la prestación médico-asistencial a la familia de los afiliados.

Por otra parte, mediante Decreto-Ley 056 de 1975, se crea el sistema nacional de salud (SNS) direccionado a tres esferas de cobertura, a saber: oficial, seguridad social y privado. Así mismo, se constituyeron los servicios seccionales de salud y las unidades regionales de salud (Decreto 350 de 1975). Ahora bien, mediante los decretos 356 y 695 de 1975 se establecieron dos formas de pertenencia de las instituciones de salud al sistema nacional de salud: a) adscripción, que incluía a todas las instituciones de derecho público y b) vinculación, de las instituciones de derecho privado. En 1976 se crea el Fondo Nacional Hospitalario, mediante el cual se obtenían recursos de los aportes del seguro de pensiones del Seguro Social y se destinaban a la ampliación de la cobertura del sector salud. En ese sentido, manifiesta el profesor Arenas Monsalve:

\begin{abstract}
En 1976 se crea el Fondo Nacional Hospitalario, que tiene recursos provenientes de los aportes del seguro de pensiones del Seguro Social [...] con ese organismo se evidenció la importancia del apoyo que el Seguro Social brindaba al sistema de salud, pues frente al volumen de recursos aportados por la entidad, "en modo alguno puede despreciarse la contribución de la seguridad social a la ampliación de la cobertura en salud".
\end{abstract}

Para el año 1979, el Gobierno Nacional, en ese amplio espectro que fijó sobre la salud pública, sanciona la Ley 9 de 1979, no solo con miras a plantear directrices sanitarias, sino también como forma de control de la calidad de la salud, mostrando el interés público al que se elevó el sector. En ese sentido lo expresa Acosta Rubio:

Desde la expedición de la Ley 9 de 1979, mediante la cual se dictan normas sanitarias, cuyo objeto tiene como fin la protección del medio ambiente, ya se daba inicio a un sistema de calidad de estructura, que estaba direccionado a la infraestructura y condiciones higiénico- sanitarias de obligatorio cumplimiento para las instituciones de salud, denominado entonces por su título IV como establecimiento hospitalario y similares, para adquirir sus licencias sanitarias, hacer apertura y poder ofertar los servicios de salud, previo sometimiento a inspección, vigilancia y control de los entes territoriales de salud y de la Superintendencia Nacional de Salud.

El tercer periodo del garantismo estatal del servicio a la salud va comprendido desde el año 1990, con la Ley 10 que se expide en aquel momento histórico, de conformidad con la Constitución Política del antiguo Estado de derecho que nos regía, como lo era la Carta Magna del año 1886, hasta la actualidad del Estado social de derecho que elevó a rango constitucional la salud como derecho fundamental, como servicio público y como parte integral del sistema de seguridad social.

La Ley 10 de 1990 fue un gran paso en la evolución de la salud en Colombia, y así lo reconocen autores como Acosta Rubio. Veamos:

Con posterioridad a la Ley 09 de 1979, se sanciona la Ley 10 de 1990 mediante la cual se organizó el sistema nacional de salud, y se define el servicio público de salud en todos los niveles de atención como un servicio público a cargo de la nación, gratuito en los servicios básicos para todos los habitantes del territorio nacional y administrado en asocio de las entidades territoriales de sus entes descentralizados y de las personas privadas autorizadas; define la forma de prestación de la asistencia pública en salud, así como las personas que tienen derecho a ella; establece los servicios básicos de salud que el Estado ofrecerá gratuitamente; fija los niveles de atención en salud y los grados de complejidad para los efectos de las responsabilidades institucionales en materia de prestación de servicios de salud $y$, en especial, los servicios de urgencias; organiza y establece las modalidades y formas de participación comunitaria en la prestación de servicios de salud; determina los derechos y deberes de los 
habitantes del territorio en relación con los servicio públicos de salud. [...] Desarrolla esta ley unos principios básicos mediante los cuales se regirá, como son: la universidad, participación ciudadana, participación comunitaria, subsidiariedad, complementariedad, integración funcional. [...] Otro aspecto importante que se reglamenta por conducto de esta Ley 10 es la prestación de servicios de salud por entidades privadas, como las fundaciones $\mathrm{o}$ instituciones de utilidad común, las asociaciones, y corporaciones sin ánimo de lucro...

En esta etapa histórica, nuestro Estado evidenció un cambio en todos los estamentos entre los que no fue ajeno el sistema de salud pública, en atención a los grandes cambios suscitados desde el ámbito constitucional con el mandado que hiciera el Constituyente del año 1991, al constituir un Estado ajustado a la modernidad y configurarlo como un Estado social de derecho que consagra derechos fundamentales, cuya prevalencia en el cometido estatal ya son una realidad y no una abstracción; he allí la consagración que más luces y proyección hizo sobre la salud, al erigirlo como derecho fundamental, pero proyectándolo más con el carácter de servicio público a cargo del Estado (art. 49) y parte de la seguridad social (art. 48).

La Corte Constitucional, en Sentencia C-636 de 2004, se pronunció en los siguientes términos respecto de la filosofía política que inspira a los Estados sociales de derecho como el que consagra nuestra Carta Magna. Veamos:

Es de la esencia de la filosofía política que inspira al Estado social de derecho la de asegurar, como cometido básico de este, inherente a su finalidad social, la atención y satisfacción de las necesidades insatisfechas de salud, educación, saneamiento ambiental, agua potable y otras, que aseguren el bienestar general y el mejoramiento de la calidad de vida, con el fin de hacer efectiva la igualdad material entre todos los integrantes de la comunidad. De este modo, la realización y la eficacia sustantiva del Estado social de derecho se mide por la capacidad de este para satisfacer, a través de la prestación de los servicios públicos, las necesidades vitales de la población, mediante el suministro de concretas prestaciones que tiendan a ello $y$, consecuentemente, de lograr por esta vía la igualación de las condiciones materiales de existencia de las personas.

Ese escenario constitucional le imprimió al Estado la obligación jurídica de satisfacer los servicios de salud, ya directa o por intermedio de agentes delegados, a fin de cumplir su fin esencial y a la vez garantizar el mencionado derecho fundamental.

Otra circunstancia que tuvo incidencia notable en la salud fueron los grandes cambios y reformas estructurales suscitadas desde el año 1990, cuando se dio un ciclo de privatización de empresas del Estado, y a la vez se propició la competencia privada para la prestación de servicios de la salud, concepción competitiva copiada del modelo chileno. De allí legislaciones como la Ley 100 de 1993, que estatuyó el régimen de seguridad social en salud que implementó un sistema para la prestación de los servicios de salud a través de una red de instituciones privadas, pero bajo el control y vigilancia del Estado por ser un fin de este sistema, que a su vez se estructuró bajo el principio constitucional de "solidaridad" en la que la financiación de los servicios de salud de los sectores de la población más pobre se aseguraba con la implementación de dos regímenes. a) Régimen contributivo, al que se vincularon sectores laborales y productivos del Estado y cuya prestación de salud se financiaba con aportes obligatorios compartidos con los empleadores, y b) régimen subsidiado, exclusivo de los sectores menos favorecidos económicamente del Estado, cuyos servicios prestacionales de salud son financiados por el sistema general de participaciones y un porcentaje de los aportes del régimen contributivo.

Como podemos ver, el escenario constitucional del año 1991 dio la categoría e importancia que la 
salud representa para una sociedad, y permitió de esa forma que aun con fallas como toda creación humana se ampliara la cobertura de salud para nuestra población y se conformara un sistema integral de salud polidimensional, que hoy día lo hace un servicio público esencial; en ese sentido lo ha expresado nuestra Corte Constitucional con ponencia del doctor Antonio Barrera Carbonell en Sentencia C-263 de 1996, en la que refiriéndose a la finalidad del Estado respecto de los servicios públicos como lo es el de salud dijo:

2.1. Los servicios públicos son inherentes a la finalidad social del Estado, y si bien su prestación no constituye un deber ineludible y exclusivo de este, es su responsabilidad asegurar su funcionamiento continuo, permanente y eficiente. Si bien inicialmente se consideró que el único prestador de servicios públicos era el Estado, la Constitución haciendo eco a la evolución de la noción en la doctrina y la jurisprudencia hizo viable su gestión no sólo por el Estado, directa o indirectamente, sino por comunidades organizadas y aún por particulares (C.P., art. 365), según lo aconsejen las conveniencias sociales y las características técnicas y económicas del servicio. Las características específicas del servicio y la naturaleza pública o privada del sujeto que lo presta determinan el régimen jurídico aplicable en cada caso, el cual nunca será puro, es decir, exclusivamente de derecho público o derecho privado, sino más bien un derecho mixto que participa de la naturaleza de ambos, sin descartar, dada la calidad de dicho sujeto, que se pueda dar una prevalencia de uno de estos derechos sobre el otro. La concepción social del Estado de derecho ha determinado una penetración de la sociedad en su actividad, hasta el punto de que no sólo reconoce, fomenta y hace efectiva la participación de la comunidad en la adopción de las decisiones que pueden afectarla y en la vigilancia de su gestión, sino que posibilita la intervención directa de sectores importantes y representativos de aquella en la prestación de determinados servicios o en la realización de actividades estatales, o en fin, de tareas o labores de utilidad o interés públicos que tienden a hacer realidad sus finalidades sociales.

La competencia para la "regulación" de las actividades que constituyen servicios públicos se concede por la Constitución a la ley, a la cual se confía la misión de formular las normas básicas relativas a: la naturaleza, extensión y cobertura del servicio, su carácter de esencial o no, los sujetos encargados de su prestación, las condiciones para asegurar la regularidad, permanencia, constancia, calidad y eficiencia en su prestación, las relaciones con los usuarios, en lo que atañe a sus deberes, derechos, al régimen de su protección y sus formas de participación en la gestión y fiscalización de las empresas que presten el servicio, el régimen tarifario, y la manera como el Estado ejerce el control, la inspección y la vigilancia para asegurar su prestación eficiente (arts. 1, 2, 56, 150-23, 365, 367, 368,369 y 370, C.P.).

Es claro que la historia de la salud en Colombia como garantía estatal siempre ha estado rodeada de puntos críticos de sostenibilidad, habida cuenta en amplio margen de cobertura y de gastos del régimen subsidiado del sector, hecho este al que no fue ajeno el sistema preparado por la Ley 100 de 1993, de tal suerte que para el año 2007 se legisló en la materia para hacer frente a la crisis. De allí surgieron normas como la Ley 1122 con la que se pretendió hacer realidad la supuesta universalidad de la Ley 100 de 1993 y de fortalecer la red pública de la prestación de salud; sin embargo, las transformaciones que ha sufrido el sector salud siempre se quedaron en legislaciones ideales que en la realidad no consiguen los objetivos y siempre caemos en la misma deficiencia, no solo asistencial sino también financiera, como aconteció en el año 2009 cuando el gobierno tuvo que decretar estado de emergencia social, que se declaró con el Decreto 4975 de diciembre 23, habida cuenta la crisis hospitalaria y de salud, y entrando a expedir diez decretos con fuerza de ley (decretos 126 a 135, de enero 21 de 2010), con los cuales se modifican 
varias normas relacionadas con el manejo de los recursos del sector Salud. Se buscó así aliviar la crisis que ese importante sector socioeconómico está enfrentando hace tiempo al recaudar fondos especiales para él. Esta declaratoria, no obstante sancionada inexequible por la Corte Constitucional en Sentencia C-252 de 2010 (m.p. Jorge Iván Palacio Palacio), tuvo unos efectos sui géneris ya que el caudal financiero amasado durante y por efectos de la emergencia social quedó incólume para no agravar la crisis que lo justificó; no obstante el gobierno, para superar de fondo el problema, presentó un proyecto de ley el cual se tramitó de forma urgente y se logró convertir en Ley de la República 1438 del 19 de enero de 2011, misma que por su novedad no ha expuesto resultados ni balances conocidos.

\section{HISTORIA DEL SISTEMA GENERAL DE SEGURIDAD SOCIAL EN COLOMBIA}

\section{Antes de la Constitución Política de año 1991}

El concepto de seguridad social es el desarrollo de aquel pilar fundamental de los Estados sociales de derecho como lo es el principio de solidaridad, entendido este no solo desde el punto de vista del reconocimiento de los derechos dentro de un Estado, sino también de la efectivización y eficacia de los mismos; en ese sentido, dice Cañón Ortega:

\begin{abstract}
El concepto de seguridad social en Colombia aparece dentro de la evolución de las instituciones sociales y jurídicas, en la misma forma que la mayoría de las sociedades, como resultado de la evolución de los mecanismos de protección social que se han venido creando a iniciativa individual, de determinados grupos sociales o del Estado, con el fin de proteger a la población en general o a algunos sectores de mayor influencia o con necesidades sociales consideradas prioritarias (p. 19).
\end{abstract}

En consonancia con ello, tenemos que la seguridad social en Colombia ha obedecido a fases evolutivas que, en criterio del profesor Arenas Monsalve, se dividen en cinco etapas, a saber:

- Periodo de dispersión: hasta 1945

- Periodo de organización del sistema: desde 1945 hasta 1967

- Periodo de expansión: desde 1967 hasta 1977

- Periodo de cambio y crisis: desde 1977 hasta 1990

- Periodo de reformas estructurales: desde 1990.

En lo que respecta al primer periodo, tenemos que por su contenido histórico fue una fase $a b$ initio precaria y de conformación del sistema, por lógica de la mano de la creación de la República y que, como tal, no evidenciaba criterios bien definidos de lo que es un sistema de seguridad social; solo fue el inicio de esas perspectivas, pero como mecanismo de respuesta a las necesidades económicas, sociales y políticas propias de una nación en formación en donde las penurias exigían respuestas de las autoridades de esa naciente República. Por este motivo, esta se fundó en el reconocimiento de beneficios en pro de quienes salvaguardan esa conformación republicana, hecho que, una vez solidificado, dio paso a la protección de la generalidad del conglomerado social, pero de una forma incipiente y como respuesta a las exigencias obreras que clamaron amparos sociales del Estado.

Este ámbito temporal de la seguridad social en Colombia, a criterio de Arenas Monsalve, tuvo cinco siguientes características sobresalientes, a saber:

1. En ausencia de esquemas de intervención estatal de este periodo, los logros en seguridad social son una combinación de beneficios asistenciales con prácticas mutuales, tanto de los militares como de los gremios artesanales y de las primeras organizaciones obreras.

[...] 2. Una segunda característica de este periodo está en que los primeros beneficios normativos de seguridad social surgen para el sector oficial y dentro de este, primero en beneficio del es- 
tamento militar y posteriormente en el personal civil oficial.

[...] 3. En la transición hacia la intervención del Estado "se aprueban leyes aisladas sobre pensiones, maternidad, sindicatos, riesgos profesionales, pago de salarios durante la incapacidad, enfermos de lepra, trabajadores petroleros y de la construcción, seguridad de vida, etc.". Aquí puede verse una normativa que es a la vez de origen reivindicativa y de "intervencionismo humanitario", es decir, que los beneficios prestacionales son simultáneamente fruto de la primera lucha obrera y de acciones humanitarias que buscan garantizar la reproducción de las fuerzas de trabajo.

[...] 4. En este primer periodo puede señalare como característica general que la legislación es fragmentaria y restrictiva. En los primeros años del siglo está orientada a un sector -el oficial- y entre este privilegia al estamento militar. Y situados ya en la fase intervencionista donde se comienza a legislar para los asalariados.

[...] 5. Finalmente en este periodo $-y$ específicamente a parir de 1928- se inician las preocupaciones por armonizar los dispersos beneficios sociales y por crear instituciones de seguros sociales que son ya conocidas en el mundo a partir de la creación en el mundo del seguro social alemán.

Ahora bien, la segunda fase evolutiva de la seguridad social en Colombia se caracterizó por darle una estructura a los beneficios en pro del conglomerado social y en especial de la clase trabajadora -de ambos sectores, el público y el privado-, a fin de moldearlos a las exigencias internacionales, $y$ en ese sentido lo expone Cañón Ortega. Veamos:

Los años 40 y 50 del siglo XX en Colombia son especialmente fructíferos en la incorporación de instituciones de protección social a la estructura social y jurídica del país, como el caso de la previsión social administrada por las cajas y fondos de precisión social, los seguros sociales obligatorios a cargo del Instituto de Seguro Social y la promulgación del
Código Laboral, para dar una protección patronal a los trabajadores asalariados por parte de sus empleadores (p. 20).

Es así como se destaca en esta segunda etapa el establecimiento precario de un régimen de subsidio familiar y la creación de cajas de compensación familiar para administrar esa prestación como formas de otorgar beneficios a la clase trabajadora y a su núcleo familiar.

De igual forma, se resalta como logro importante de etapa la creación del SENA (Decreto 118 de 1957 y ley 188 de 1959) como esquema de capacitación de los trabajadores colombianos y manera de tecnificar a los aprendices, de conformidad con la Organización Internacional del Trabajo. Por otra parte, se estructura la piedra angular de la seguridad social en Colombia, como lo fue la creación del Seguro Social (Ley 90 de 1946). Ahora bien, en este periodo se legisló en pro de beneficios de la clase trabajadora, logrando esta la denominada pensión sanción (Ley 171 de 1961) como prestación social atípica de estabilidad laboral.

En lo que respecta a este periodo de evolución, es claro el profesor Arenas Monsalve al destacar el eje organizativo que rodeó la seguridad social como cometido estatal, y para ello hizo uso del poder legislativo, no solo creando organismos que desarrollaran dicha actividad en ambos sectores -el privado y el público-, sino también fortaleciendo la legislación laboral como derecho socioeconómico; entre otras, las principales características según el autor en cita son:

1. En primer lugar, esta es la época del establecimiento formal de una legislación general y relativamente uniforme para las relaciones laborales (D. 2350/44 y L. 6a/45), tanto para los trabajadores del sector público como del sector privado. Dentro de dicha legislación se establecen igualmente los beneficios de seguridad social como prestaciones sociales a cargo del empleador, separando también el sistema prestacional de los sectores público y privado. 
[...] 2. Para el sector privado, las prestaciones sociales se establecen con una característica básica: la transitoriedad de las mismas en cabeza de los empleadores, hasta que se creara una entidad estatal de seguridad social. Con la Ley 90 de 1946 se cristaliza la creación del Instituto Colombiano de los Seguros Sociales como una entidad técnicamente diseñada para administrar un régimen de seguros sociales obligatorios que reemplazaría a los empleadores en el reconocimiento y pago de las principales prestaciones sociales.

[...] 3. Con respecto al sector público, la normativa de 1945 tomó varias decisiones de trascendencia: creó las prestaciones sociales, fundó la Caja Nacional de Prevención y autorizó la creación de otras cajas oficiales. Los efectos de estas decisiones marcaron el rumbo de la seguridad social oficial hasta la expedición de la Ley 100 de 1993.

[...] 6. El debate sobre el establecimiento de los seguros económicos de la seguridad social fue un debate complejo. Fueron factores en contra de dicha ampliación la imagen negativa de algunos servicios asistenciales del ICSS, la crítica al déficit creado por el gobierno en el Instituto y el rechazo de los gremios al aseguramiento público de los riesgos [...]. Finalmente en el año 1964 se inicia la vigencia del seguro de riesgos profesionales y en 1966 se da comienzo al seguro de pensiones.

Una vez cimentada la estructura administrativa y legislativa de la seguridad social de conformidad con lo expuesto en el periodo anterior, se produjo un tercer periodo en la historia de la seguridad social colombiana, y es el denominado como expansivo, en el cual el Estado proyectó el sistema en cobertura y beneficios. Es así como tenemos que puesto en marcha el Instituto Colombiano de Seguros Sociales sus servicios se extendieron a la cobertura de seguros de invalidez, vejez y muerte (Decreto 1824 de 1965), como forma de distribución racional de las actividades económicas del Estado ya organizado desde el punto de vista social, pero ahora llevando dichos beneficios a un mayor núcleo poblacional y regional, no solo desde el punto de vista prestacional de la salud y pensional (se expidieron leyes de beneficio pensional como la $4^{\text {a }}$ de 1976, estatuto del pensionado, y la 33 de 1973), sino también de las coberturas familiares brindadas por las cajas de compensación familiar, a las que se les erigió medios eficaces de control de su labor social en la administración de subsidios a los núcleos de población favorecidos por esta proyección social.

De igual forma, se expandió la fortaleza respecto de las prestaciones sociales de los trabajadores del sector público (Decreto-Ley 3135 de 1968) y, así mismo, se asignó al Fondo Nacional del Ahorro (Decreto-Ley 3118 de 1968) la función de administrador de las cesantías de este sector laboral público, todo con miras a la proyección de vivienda del sector y de paso a la protección familiar como formas de seguridad social.

En ese proceso expansionista del sistema de seguridad social, un papel importante desempeñó la salud, ya que el Estado asumió por fin el rol que le asignó la Constitución Nacional en el acto legislativo del año 1936, esto es, como un cometido importante para el logro efectivo de ese sistema de seguridad social, es decir, como fin público estatal, y como tal, entendió que es al Estado a quien corresponde la obligación asistencial de salud de sus asociados, no solo desde el punto de vista de la calidad, sino también de la cobertura. Fue así como se crea el sistema nacional de salud y el Fondo Nacional Hospitalario en el año 1976 como formas de masificación de la atención en salud de la población menos favorecida.

Al respecto es del caso tener presente lo expuesto por el profesor Cañón Ortega. Veamos:

Con la incorporación del concepto de asistencia pública de la Constitución Política de 1886, mediante Acto Legislativo No. 1 de 1936, como una responsabilidad a cargo del Estado en favor de todas las personas que carecen de medios de 
subsistencia y de derecho a reclamar protección de otras personas o sistemas, o que estuvieron físicamente incapacitadas para trabajar, el Estado asume la responsabilidad de dar protección a buena parte de la población no trabajadora.

En desarrollo de la asistencia pública, el Estado complementaba así la ayuda que venía dando a las denominadas instituciones de utilidad común, de carácter privado y de beneficencia pública, mediante creación del Ministerio de Higiene y del Plan Hospitalario Nacional, respectivamente, con el fin de definir políticas, adelantar campañas, construir infraestructuras hospitalarias y destinar recursos fiscales y de deudas externas para ofrecer servicios de asistencia pública, a través de una red de instituciones que posteriormente vinieron a conformar lo que se llamó por cerca de dos décadas el sistema nacional de salud.

Bajo los conceptos de beneficencia pública, asistencia pública, asistencia social, salubridad, higiene, salud pública y salud, el país construyó un importante sistema de protección social para la población no trabajadora, con recursos, políticas e instituciones de Estado, que durante la segunda mitad del siglo XX dio protección en salud a dicha población, mediante acciones que comprendían desde los programas de salud pública y de atención materno-infantil hasta la atención hospitalaria en los diferentes niveles de atención con cargo a los recursos del Estado (p. 25).

Ahora bien, esa fase tercera de expansión del sistema de seguridad social en Colombia fue el preámbulo de lo que sería el cuarto periodo, identificado por la crisis del sistema y en especial del ente público pilar del mismo, como lo fue el Instituto de Seguros Sociales, derivado del hecho de la amplitud desmesurada de la cobertura y de las falencias administrativas que rodearon el sector; de allí que el profesor Arenas Monsalve le destaque esa característica a esa fase; veamos:

En este periodo se hace evidente también la crisis burocrática y administrativa en el Seguro Social, y se empieza a planear su solución global. Importantes medidas normativas se producen en el régimen jurídico y financiero del Instituto; la institución de que se tenga noticia (p. 91).

En lo que respecta al cuarto periodo, tenemos que se caracteriza como una etapa de problemática suscitada por la crisis dada en el seno del Instituto de Seguro Social (desorden administrativo, corrupción y paro medio) y por deficiencias que el sistema de seguridad social conformado mostró en el contexto social y económico del país. Esto se sintetiza en que aquel sistema era disipado, con una cobertura precaria que dejaba por fuera a las clases más pobres; que el ámbito de protección dejaba de amparar algunos riesgos sociales; que no daba tratamiento igual a toda la clase trabajadora, en especial para con los que ejercían labores de forma independiente; $y$ como si fuere poco un sistema con un grado alto de déficit financiero, que comprometió el funcionamiento del mismo en los términos en que estaba estructurado por la ausencia de mecanismos de financiación; esto es, el sistema no solo había quedado ineficaz, sino también ineficiente, lo que urgió reformas estructurales y reorganización en el Seguro Social (Decreto-Ley 1650 de 1977), en especial en la separación de la administración de los riesgos asistenciales de los económicos; en el régimen de subsidio familiar (leyes 25 de 1981 y 21 de 1982), incluyendo el control estatal en ese sistema, y reformas pensionales (leyes 33 de 1981 y 71 de 1988).

Esta etapa, en sentir del profesor Arenas Monsalve, fue de "cambios y crisis" en atención a que se caracterizó por:

1. En primer lugar, las dificultades institucionales del Seguro Social determinan la expedición de una ley de facultades al Presidente de la República (L. 12/77) para reorganizar todo el régimen de seguros sociales en el país. Con la normatividad expedida (D.L. 1650 de 1977) se buscaba un mejoramiento en los recursos y servicios de la entidad, pero esa oportunidad terminó en una restructuración parcial 
del Seguro Social, cuyo contenido no se aplicó plenamente.

2. En este periodo se pone fin a la crisis sindical y de personal en el ISS con la expedición de un régimen especial que crea "funcionarios de seguridad social" de instituto, como una categoría especial e intermedia entre empleados públicos y trabajadores oficiales.

[...] 4. Una de las prestaciones del sistema de seguridad social, las asignaciones familiares o subsidio familiar, así como las instituciones que la administran -las cajas de compensación familiar- sufren en este periodo unos cambios institucionales fundamentales que aún conservan su línea básica. Estos cambios institucionalizaron la intervención estatal en el sistema, y estuvieron acompañados de diversas tensiones entre el Estado y las entidades del sistema.

5. En esta etapa se produce una transformación radical de la llamada "pensión sanción". El gobierno resuelve modificar el reglamento general del seguro de pensiones, con la expedición (D. 2870/85) que establece que la pensión sanción se integra con la vejez que reconozca el seguro.

[...] 6. En este periodo se producen interesantes esfuerzos legislativos en materia de pensiones, con la expedición de las leyes 33 de 1985 y 71 de 1988, con sus correspondientes reglamentaciones. En estas leyes se reestructuran las condiciones pensionales en el sector oficial, se fortalece financieramente a las entidades, se modifica el Estatuto del Pensionado y se ordena en futuro la unificación de los tiempos pensionales en sector público y privado.

\section{Desde la Constitución Política del año 1991}

Es claro que el contexto histórico de nuestro país fue otro a partir del año 1990 y la presidencia del doctor César Gaviria, ya que este recopiló todo el movimiento político, social y económico que por aquella década movía el contexto mundial, me refiero al proceso de globalización que encontraba en nuestra estructura estatal talanqueras, habida cuenta el escenario histórico en que la Carta Magna de 1886 que nos regía había nacido. Ese lapso histórico posibilitó la conformación de una Asamblea Nacional Constituyente para estructurar no solo una nueva carta constitucional, sino también un nuevo modelo de Estado moderno, como el que efectivamente se erigió "Estado social de derecho", en el que la salud tomó la forma de derecho fundamental (art. 49), de servicio público (art. 49) y de parte integrante de la seguridad social (art. 48).

Ahora, nuestro máximo Tribunal Constitucional, en Sentencia C-655 de 2003, consideró la seguridad social como:

El conjunto de medidas institucionales dirigidas a proteger al individuo y a sus familias de las consecuencias nocivas que generan los distintos riesgos sociales a que se encuentran expuestos, y cuya ocurrencia puede afectar en forma significativa su capacidad y oportunidad de proveer los recursos necesarios en orden a garantizar una subsistencia digna.

Su objetivo es propiciar la prosperidad de los asociados con apoyo en los programas que desarrollen los distintos gobiernos, los cuales deben estar dirigidos a permitir que el individuo, y su familia, pueda afrontar adecuadamente las contingencias derivadas de las enfermedades, la invalidez, el desempleo, el subempleo y las consecuencias de la muerte; a brindarle adecuada protección a ciertos estados propios de la naturaleza humana, como la maternidad y la vejez, y a ofrecerle unas condiciones mínimas de existencia y recreación social que le permitan desarrollarse física y sicológicamente en forma libre y adecuada, facilitando de este modo su total integración a la sociedad.

En consonancia con la consagración constitucional y la categoría e importancia de la seguridad social en el nuevo marco constitucional, se han suscitado grandes cambios en el sistema, no obstante ya 
antes de la reforma magna y como preámbulo del nuevo escenario se presentaron algunos ajustes en el ámbito laboral, como el de la Ley 50 de 1990, que flexibilizaron las relaciones obrero-patronales, se ampliaron algunas coberturas prestacionales y se creó el sistema privado de administración de las cesantías y de pensiones mediante la Ley 45 de 1990; así mismo, se extendieron los mecanismos proteccionistas sindicales, pero a la vez se reestructuró y reorganizó el Estado, con la supresión o fusión de entidades, y el retiro masivo de funcionarios públicos, bajo modalidades de indemnización (Ley 60 de 1990, Decreto 1160 de 1991). Luego, lo anterior se elevó a rango constitucional de forma momentánea (art. 20 transitorio, C.N.) y se aprovechó por el gobierno de turno para que mediante Decreto 2148 de 1992 se reestructuraran el Instituto de Seguros Sociales, La Caja Nacional de Previsión (Decreto 2147 de 1992), el Ministerio del Trabajo y Seguridad Social (Decreto 2145 de 1992), el Ministerio de Salud (Decreto 2164 de 1992), el SENA (Decreto 2149 de 1992) y otras muchas entidades públicas.

El nuevo orden constitucional trajo consigo la necesidad que erigir un sistema de seguridad social para lograr los fines constitucionales; fue así como se expidió el pilar fundamental del sistema integral de la seguridad social: la Ley 100 de 1993 que, como lo expresa el profesor Arenas Monsalve, se caracterizó por:

2. El sistema integral de seguridad social tiene algunas características que son comunes a los sistemas que lo componen: presencia del Estado en la dirección y control; gestión pública y privada; obligatoriedad de la afiliación, protección centrada en la población asalariada formal; financiamiento mediante cotizaciones, y, finalmente, respeto a la creación de beneficios mediante la negociación colectiva.

3. El sistema general de pensiones fue establecido como sistema dual en el cual coexisten el régimen tradicional del seguro social (denominado en la ley “régimen solidario de prima media con prestación definida" con el nuevo régimen de capitalización llamado en la ley "régimen de ahorro individual con solidaridad". [...]

4. El sistema general de seguridad social en salud constituyó un esfuerzo institucional significativo: se crearon dos regímenes, uno para la población con capacidad de cotización y otro para los sectores de población en situación de marginalidad (denominado "régimen subsidiado").

5. El sistema general de riesgos profesionales se previó como un sistema técnico de aseguramiento [...].

Ahora bien, en lo que respecta al sistema de seguridad social en salud que creó la Ley 100 de 1993, tenemos que tuvo entre otras las siguientes características principales:

Separación de la prestación, administración y financiamiento del servicio. En tal sentido, se crearon las entidades promotoras de salud, EPS, encargadas de la afiliación, recaudo y garantía del acceso al plan de servicios. La prestación de servicios está a cargo de las instituciones prestadoras de salud, IPS, las cuales pueden ser oficiales, mixtas, privadas o solidarias.

Estímulo a la cobertura universal. El sistema señala como obligatoria la afiliación de todos los colombianos, previo pago de una cotización reglamentaria o a través de subsidios. Se afilian los trabajadores dependientes, independientes, con su familia, y se garantizan subsidios a las personas sin capacidad económica.

Otorgamiento de un plan integral. Existe un plan integral de protección a la salud cuyo propósito es cubrir a todas las personas sin discriminación, sin importar sus ingresos o riesgos específicos, en las fases de promoción, prevención, diagnósti$\mathrm{co}$, tratamiento y rehabilitación.

[...] Sustitución de la asistencia pública. A las personas sin capacidad económica se les garantiza el acceso al sistema a través del aseguramiento por subsidio a la demanda, los cuales son administra- 
dos por los administradores de regímenes subsidiados, ARS. [...]

[...] Creación de un fondo para régimen subsidiado. Se crea un aporte obligatorio financiado por los cotizantes y aportantes estatales para asegurar el acceso de todos los colombianos (Torres, 2003).

Ya en el nuevo escenario constitucional y legal de la seguridad social, se ha moldeado la estructura y el mantenimiento del sistema habida cuenta el gran costo presupuestal que implica. He allí que se hubieren amoldado algunas exigencias constitucionales y legales a la viabilidad del sistema estructurado, encontrando así modificaciones al sistema de salud como el Acto Legislativo 1 de 2002 y la Ley 715 del mismo año, que rediseñaron la financiación del régimen subsidiado a través de las modificaciones pertinentes al sistema de transferencia de los entes territoriales. De igual forma, encontramos que se creó, mediante la Ley 789 de 2002, el sistema de protección social con miras a lograr la cobertura de los más desprotegidos del sistema general. En el ámbito pensional, se expidió la Ley 797 de 2002 que introdujo variaciones notables en el sistema de pensiones, verbigracia en el cálculo, los subsidios del sistema de pensiones. De igual forma, se crearon mecanismos de control para evitar la evasión de las afiliaciones y cotizaciones. Así mismo, se ensayaron medios constitucionales (referendo) para lograr reformas pensionales radicales que no lograron pasar el escollo del análisis de constitucionalidad (Sentencia C-551 de 2003). No obstante, se insistió por la vía de la reforma del legislador a la Constitución Nacional, logrando parcialmente sus frutos el proyecto de acto reformatorio con el Acto Legislativo 1 de 2005, el cual trajo consigo la terminación de los regímenes especiales de pensión, el aumento de las edades $y$, en fin, toda una serie de modificaciones altamente cuestionadas por los sectores laborales del país.

Por otra parte, como ha sido la constante del sistema desde sus orígenes precarios, la financiación por parte del Estado en el régimen subsidiado se torna insostenible, igual que en el sector, motivando la expedición de la Ley 1122 de 2007, mediante la cual se introdujo una reforma al sistema contributivo del sistema de salud para poder solventar el funcionamiento del régimen subsidiado; de paso, se opta por remplazar el sector salud manejado por el Seguro Social, creando prima facie un proceso de escisión de las clínicas y transformación en empresas sociales del Estado, para darle paso a una nueva promotora de salud y desahogar el sector público de salud asumido por este ente que en sentir del Estado era improductivo e inviable financieramente. Pareciera que es por improvisación estatal que se da el mal del sistema de seguridad social en salud; a la fecha no ha variado y para el año 2010 nuevamente surgió la crisis del sector, por lo que ya hizo carrera como "insostenibilidad financiera", al punto que el Gobierno Nacional, a través del Decreto 4975 de diciembre 23 de 2009, estableció la emergencia social del sector salud, la cual fue declarada inexequible por la Corte Constitucional mediante Sentencia C-252 de 2010 (m.p. Jorge Iván Palacio Palacio). Por esta razón el Gobierno Nacional acudió a las labores prioritarias del Congreso de la República para legislar en la materia, lo cual surtió sus frutos con la expedición de la Ley 1438 del 19 de enero de 2011, que se proyecta como una de las tantas soluciones esperadas de antaño para el sector salud.

\section{REFERENCIAS}

Acosta Rubio, N. (2008). El derecho de la oferta de servicios de salud en colombia y las autoridades administrativas en vía gubernativa. (1 ${ }^{\mathrm{a}}$. ed.). Bogotá, Colombia: Ediciones Doctrina y Ley Ltda.

Arenas Monsalve, G. (2007). El derecho colombiano de la seguridad social. (2ª ed.). Bogotá, Colombia: Legis Editores S.A.

Barrera Carbonell, A. (m. p.). (1996, junio 13). Sentencia C-263. Bogotá, D.C., Colombia: Corte Constitucional. 
Barrera Carbonell, A. (m. p.). (2000, mayo 31). Sentencia C-636. Bogotá, D.C., Colombia: Corte Constitucional.

Barrera Carbonell, A. (m. p.). (2000, junio 8). Sentencia C-663. Bogotá, D.C., Colombia: Corte Constitucional.

Cañón Ortega, L. (2007). Una visión integral de la seguridad social. (1) (2a . ed. actualizada). Bogotá, Colombia: Universidad Externado de Colombia.

Carrasco, E. (Coord.). (2003). Diez años del sistema de seguridad social colombiano. Evaluación y perspectiva. Bogotá, Colombia: Universidad Externado de Colombia.

Constitución Política de Colombia. (2010). Bogotá, Colombia: Legis Editores S.A.

Contreras Bautista, J.D. (2009). Derecho y economía de la salud en Colombia. (1 ${ }^{a}$. ed.). Bogotá, Colombia: Librería Ediciones del Profesional Ltda.

Dávila Vinueza, L.G. (2003). Régimen jurídico de la contratación estatal. Aproximación crítica a la Ley 80 de 1993. (2ª. ed.). Bogotá, Colombia: Legis Editores S.A.

Estatuto General de la Contratación de la Administración Pública. (2010). (1 ${ }^{\text {a }}$. ed.). Bogotá, Colombia: Legis Editores S.A.

Hernández, M. y Obregón, D. (2010). La Organización Panamericana de la Salud y el Estado coIombiano. Cien años de historia. Recuperado el 8 de diciembre de http://aprendeenlinea.udea.edu. co/lms $/$ moodle $/ \mathrm{mod} /$ resource/view.php?id=20761
Miranda Talero, A. (1995). El derecho de la seguridad social. (1 ${ }^{a}$. ed.). Bogotá, Colombia: Pontificia Universidad Javeriana, Facultad de Ciencias Jurídicas.

Olano Valderrama, C.A. y Olano García, H.A. (2000). Derecho constitucional e instituciones políticas. Estado social de derecho. (3a. ed.). Bogotá, Colombia: Editorial Librería del Profesional.

Organización Mundial de la Salud. (2010). Recuperado el 7 de diciembre de http://www.who.int/ publications/es/

Orozco Africano, J. (2010). Caracterización del mercado del aseguramiento en salud para el régimen contributivo en Colombia. Recuperado el 8 de diciembre de http://www.eumed.net/ libros/2008b/386/Antecedentes\%20del\%20Sistema\%20General\%20de\%20Seguridad\%20Social\%20 en\%20Salud.htm

Sierra Porto, H. (m. p.) (2007, agosto 15). Sentencia T-636. Bogotá, D.C., Colombia: Corte Constitucional.

Solano Sierra, J.E. (2010). Contratación administrativa. (4 ${ }^{a}$. ed. actualizada). Bogotá, Colombia: Ediciones Doctrina y Ley Ltda.

Torres Corredor, H. (Comp.). (2003). Sistema de seguridad social salud. Legislación. (2a . ed.). Bogotá, Colombia: Universidad Nacional de Colombia.

Vélez Arango, A. (2010). Nuevas dimensiones del concepto salud. El derecho a la salud en el Estado social de derecho. Recuperado el 7 de diciembre de http://promocionsalud.ucaldas.edu.co/downloads/Revista\%2012_6.pdf 